\title{
Short-term intraocular pressure changes after intravitreal injection of bevacizumab in diabetic retinopathy patients
}

This article was published in the following Dove Press journal:

Clinical Ophthalmology

25 March 2014

Number of times this article has been viewed

\author{
Qasim Kadhim Farhood' \\ Sinan Mohammad Twfeeq ${ }^{2}$ \\ 'College of Medicine, Babylon \\ University, Babylon; ${ }^{2} \mathrm{Al}-$ Jumhori \\ teaching hospital, Mosul, Iraq
}

Background: This study examined the changes in short-term intraocular pressure (IOP) in a prospective series of patients undergoing intravitreal bevacizumab injection. The aim was to evaluate the frequency and predictive factors related to intraocular pressure (IOP) elevation in patients receiving intravitreal bevacizumab.

Patients and methods: This study included 52 patients with diabetic retinopathy between 28 to 75 years of age with a mean age of 51 years; 30 (58\%) were females, and $22(42 \%)$ were males. All patients received bevacizumab $(1.25 \mathrm{mg} / 0.05 \mathrm{~mL})$ injected intravitreally in a standard fashion between May 2012 to February 2013 in the AL-Jumhoury teaching hospital. IOP was measured at baseline, 5, 10, and 30 minutes after injection using Goldman applanation tonometry.

Statistics: Data were analyzed using the SPSS v.12.0 for windows. Basic, demographic, and clinical data were analyzed using means, proportions, and appropriate $95 \%$ confidence intervals (CIs).

Results: Most patients ( $85 \%$ ) were diagnosed with proliferative diabetic retinopathy, while 15\% presented with diabetic macular edema. The mean IOP values at baseline, 5, 10, and 30 minutes after injection were $14.0 \mathrm{mmHg}(95 \%$ CI 13.4-14.7), $36.1 \mathrm{mmHg}$ (95\% CI 33.5-38.6), 25.7 $\mathrm{mmHg}$ (95\% CI 23.8-27.5), and $15.5 \mathrm{mmHg}$ (95\% CI 12.4-16.51), respectively. Regression analysis showed a trend toward phakic patients having higher IOP at 30 minutes.

Conclusion: Intravitreal injection of bevacizumab is safe with respect to short-term IOP changes, as almost all IOP returned to a safe range $(<25 \mathrm{mmHg})$ within 30 minutes. Elevated IOP 30 minutes after injection only occurs rarely, so routine prophylactic use of anti-glaucoma medication is not indicated.

Keywords: intravitreal injection, bevacizumab, intraocular pressure, Goldmann applanation tonometry

\section{Introduction}

Bevacizumab (Avastin ${ }^{\circledR}$ F. Hoffmann-La Roche Ltd., Basel, Switzerland) is a humanized monoclonal antibody that inhibits endothelial growth factor, and is rapidly becoming one of the leading treatments for neovascular age-related macular degeneration (AMD). ${ }^{1}$ There is growing evidence of the benefits of bevacizumab for treating other ocular diseases associated with neovascularization, such as diabetic retinopathy. ${ }^{2}$ Also, bevacizumab has been reported to cause rapid regression of anterior segment neovascularization in eyes with neovascular glaucoma. ${ }^{3}$

Intravitreal vascular endothelial growth factor (VEGF) antagonists are now being used by ophthalmologists to treat various ischemic retinal disorders ${ }^{4}$ and to improve vision in patients with macular edema due to diabetic retinopathy and vein occlusion. ${ }^{5}$ The largest
Correspondence: Qasim Kadhim Farhood College of Medicine, Babylon University, Babylon

Email qasim_1964@ymail.com 
collection of data concerning the safety of bevacizumab was compiled by the International Intravitreal Bevacizumab Safety Survey, ${ }^{1}$ which reported on complications, such as endophthalmitis, cataract progression, subretinal hemorrhages, and retinal tears. However, as that report relied on voluntary reporting to ascertain complication rates, underestimation of these rates seems quite possible. Furthermore, the role of intraocular hypertension was not studied quantitatively.

Numerous published reports highlight the potential for a significant rise in intraocular pressure (IOP) following intravitreal injections in general. ${ }^{6-8}$ An acute rise in IOP has been shown in animal models to block axonal transport to the optic nerve head; in addition, a higher rise in IOP is associated with more severe damage. ${ }^{9}$ An acute rise in IOP has also been shown to decrease juxtapapillary retinal and optic nerve head blood flow proportionally to the quantitative rise in IOP. $^{10}$

Three studies have investigated the short-term changes in IOP following intravitreal injection of triamcinolone acetonide (TA). ${ }^{6-8}$ A study by Benz et $\mathrm{al}^{6}$ showed that the IOP normalized in most patients 30 minutes after injection, but $10 \%$ of patients who did not have vitreous reflux after injection had an IOP greater than $25 \mathrm{mmHg}$ at 30 minutes. The mechanism for the short-term IOP rise immediately after intravitreal injection of TA was thought to be a result of the increase in volume of the vitreous cavity after injection. As the intravitreal use of bevacizumab is growing exponentially, the safety of this procedure is of fundamental importance. Given the potential for significant IOP elevation in the immediate post-injection period, we investigated the changes in IOP following a 0.05 $\mathrm{mL}$ intravitreal bevacizumab injection in order to outline more clearly the safety of this novel treatment modality.

\section{Patients and methods}

A prospective case series of 52 patients undergoing intravitreal injection of bevacizumab at the ophthalmology department, Al-Jumhori teaching hospital, Mosul, Iraq, from May 2012 to February 2013 was included in this study. Patient ages ranged from 28 to 75 years (mean 51.5; Table 1). To maximize generalizability, exclusion criteria were kept to a minimum, and included previous ocular surgeries or intravitreal injections of corticosteroid within the previous 3 months. Ethics approval was obtained and informed consent was attained from each patient in the study.

\section{Technique}

Intravitreal injections were given using similar techniques. Demographic and clinical data (Table 1) were collected
Table I Demographic and clinical characteristics of the study sample

\begin{tabular}{|c|c|}
\hline Variable & Number (\%) \\
\hline \multicolumn{2}{|l|}{ Sex } \\
\hline Female & $30(57.6)$ \\
\hline Male & $22(42.4)$ \\
\hline \multicolumn{2}{|l|}{ Age, years } \\
\hline $28-49$ & $21(40.3)$ \\
\hline $50-59$ & $20(38.4)$ \\
\hline $60-69$ & $7(13.4)$ \\
\hline $70+$ & $4(7.7)$ \\
\hline \multicolumn{2}{|l|}{ Glaucoma } \\
\hline Present & $16(15.4)$ \\
\hline \multicolumn{2}{|l|}{ Diagnosis } \\
\hline Proliferative diabetic retinopathy & $44(84.6)$ \\
\hline Diabetic macular edema & $8(15.4)$ \\
\hline \multicolumn{2}{|l|}{ Injection number } \\
\hline One & $16(30.7)$ \\
\hline Two & $25(48.0)$ \\
\hline Three & $10(19.2)$ \\
\hline Four & I (I.9) \\
\hline \multicolumn{2}{|l|}{ Eye } \\
\hline OS & $30(57.6)$ \\
\hline OD & $22(42.4)$ \\
\hline \multicolumn{2}{|l|}{ Lens status } \\
\hline Phakic & $29(55.7)$ \\
\hline Pseudophakic & $23(44.3)$ \\
\hline
\end{tabular}

Abbreviations: OS, oculus sinister (left eye); OD, oculus dexter (right eye).

through patient interview and chart review. Visual acuity and IOP values were obtained at baseline. Patients were prepared and draped in a standard fashion and positioned supine for the procedure. A solution of $10 \%$ povidone-iodine was used for sterilization; a wire lid speculum was applied for lid control, and before injection, topical antibiotic drops (5\% povidoneiodine solution and topical $0.5 \%$ proparacaine drops) were instilled into the conjunctiva. The intravitreal bevacizumab injection was prepared by drawing-up approximately $0.1 \mathrm{~mL}$ of bevacizumab $(2.50 \mathrm{mg} / 0.1 \mathrm{~mL})$ into a $1.0 \mathrm{~mL}$ tuberculin syringe. The excess was removed, and the remainder $0.05 \mathrm{~mL}$ (1.25 mg) was injected with a 30 -gauge needle through the inferotemporal or inferonasal pars plana at $3.0 \mathrm{~mm}$ or $3.5 \mathrm{~mm}$ posterior to the limbus if the patient was pseudophakic or phakic, respectively. The needle was inserted approximately $1.0 \mathrm{~cm}$ into the globe, and the injection was performed. After injection, a sterile cotton swab was placed on the injection site to prevent reflux of the medicine, and one drop of topical moxifloxacin was instilled (Vigamox; Alcon Laboratories Inc., Fort Worth, TX, USA). Thereafter, prophylactic topical moxifloxacin drops were continued for a few days.

Patients were examined by slit-lamp, and an IOP measurement was performed at 5, 10, and 30 minutes after injection using Goldmann applanation tonometry. If the 
IOP was $\geq 25 \mathrm{mmHg}$ after 30 minutes then the patient was observed for another 1.5 hours and if the IOP was still elevated anti-glaucoma medication was prescribed.

To investigate the reliability of IOP measurements between the two observers, an interobserver reliability study was performed. In a random group of patients not involved in the study and with normal intraocular pressure, IOP was measured by both of the observers consecutively. Both observers were blind to any previous IOP measurements in the patient chart, and the second observer was blind to the IOP measurement taken by the first observer. An intraclass correlation coefficient was used to assess inter-rater reliability of IOP measurements between the two examiners.

Data were analyzed using the Statistical Package for the Social Sciences v. 12.0 for Windows (SPSS Inc., Chicago, IL, USA). Basic demographic and clinical data were analyzed using means, proportions, and appropriate $95 \%$ confidence intervals (CIs). The main outcome measure was the proportion of patients with an IOP above $24 \mathrm{mmHg}$ at 30 minutes after injection. A secondary outcome measure was the proportion of patients with an IOP $\geq 5 \mathrm{mmHg}$ above baseline at 30 minutes after injection. Multivariate logistic regression analysis with backward selection (exclusion of $P \geq 0.10$ ) was used to simultaneously investigate factors associated with increased IOP after 30 minutes.

\section{Results}

Fifty-two diabetic retinopathy patients were included in this study, 30 (57.6\%) of whom were female and $22(42.4 \%)$ were male, with a mean age of 51 (standard deviation 10.33) years. Most patients (84.6\%) were receiving intravitreal bevacizumab injections for neovascularization due to diabetic retinopathy. Table 1 shows basic demographic and clinical data of the studied patients.

We sampled 41 patients randomly for our interobserver reliability study. IOP measurements were within $3 \mathrm{mmHg}$ in $90.2 \%$ of cases. The intraclass correlation coefficient between observers was 0.87 (95\% CI 0.77-0.93).

For all studied patients, the mean IOP values (Table 2 and Figure 1) at baseline, 5, 10, and 30 minutes after injection were $14.0 \mathrm{mmHg}(95 \% \mathrm{CI} 13.4-14.7), 36.1 \mathrm{mmHg}$ (95\% CI $33.5-38.6), 25.7 \mathrm{mmHg}$ (95\% CI 23.8-27.5), and $15.5 \mathrm{mmHg}$ (95\% CI 12.4-16.51), respectively. Patients with a history of glaucoma ( $\mathrm{n}=16)$ had higher baseline IOP $(P=0.041)$.

Table 2 shows the range of IOP values at baseline and at the three post-injection intervals. IOP increased sharply 5 minutes after injection $(P<0.0005)$; four patients $(7.69 \%)$ had an IOP 50-59 mmHg and one patient had an IOP over
Table 2 Intraocular pressure at baseline and at various times after intravitreal injection of bevacizumab

\begin{tabular}{|c|c|c|c|c|}
\hline \multirow{2}{*}{$\begin{array}{l}\text { IOP } \\
(\mathrm{mmHg}) \text {, } \\
\text { range }\end{array}$} & \multicolumn{4}{|c|}{ Number (\%) } \\
\hline & Baseline & $\begin{array}{l}5 \text { minutes } \\
\text { after } \\
\text { injection }\end{array}$ & $\begin{array}{l}10 \text { minutes } \\
\text { after } \\
\text { injection }\end{array}$ & $\begin{array}{l}30 \text { minutes } \\
\text { after } \\
\text { injection }\end{array}$ \\
\hline $0-19$ & $49(94.23)$ & $5(9.61)$ & $16(30.8)$ & 4 I (78.8) \\
\hline $20-24$ & $2(3.84)$ & $8(15.38)$ & II (2I.2) & $9(17.3)$ \\
\hline $25-29$ & $\mathrm{I}(1.92)$ & $6(11.53)$ & $10(19.2)$ & $\mathrm{I}(1.92)$ \\
\hline $30-34$ & - & $9(17.3)$ & $6(11.53)$ & - \\
\hline $35-39$ & - & $7(13.46)$ & $3(5.8)$ & - \\
\hline $40-44$ & - & $6(11.53)$ & $4(7.69)$ & - \\
\hline $45-49$ & - & $6(11.53)$ & - & I (1.92) \\
\hline $50-59$ & - & $4(7.69)$ & $\bar{I}(1.92)$ & - \\
\hline $60-69$ & - & $\mathrm{I}(1.92)$ & I (1.92) & - \\
\hline Mean IOP & $14.1 \mathrm{mmHg}$ & $36.1 \mathrm{mmHg}$ & $25.7 \mathrm{mmHg}$ & $15.5 \mathrm{mmHg}$ \\
\hline $95 \% \mathrm{Cl}$ & $13.4-\mid 4.7$ & $33.5-38.6$ & $23.8-27.5$ & $|2.4-| 6.5 \mid$ \\
\hline$P$-value & & $<0.0005$ & & $<0.02$ \\
\hline
\end{tabular}

Abbreviations: $\mathrm{Cl}$, confidence interval; IOP, intraocular pressure.

$60 \mathrm{mmHg}$. Over the next 30 minutes, IOP returned back to normal; however, at 5 and 30 minutes after injection, the mean IOP remained statistically significantly above baseline $(P<0.0005$ and $P<0.02$, respectively). Thirty minutes postinjection, nine patients (17.3\%) had IOPs $5 \mathrm{mmHg}$ greater than baseline values, but for only two patients (3.84\%) the IOP was higher than $25 \mathrm{mmHg}$ after 30 minutes. The IOP of one of those patients (with a 30 minute value of $28 \mathrm{mmHg}$ ) returned to under $25 \mathrm{mmHg}$ within 2 hours and did not require initiation of anti-glaucoma medication. The other patient, whose IOP at 30 minutes was $45 \mathrm{mmHg}$ and still elevated after 2 hours post-injection, required initiation of anti-glaucoma medication; the IOP was controlled within 1 week, and the anti-glaucoma medication was discontinued at that time. A multivariate logistic regression analysis was used to investigate factors related to higher IOP at 30 minutes after injection. Since only a small proportion of patients had an IOP of $\geq 25 \mathrm{mmHg}$ at 30 minutes (primary outcome), we used the secondary outcome measure (IOP $\geq 5 \mathrm{mmHg}$ above baseline) as our dependent variable in the regression analysis. Regression analysis showed a trend toward phakic patients having higher IOP at 30 minutes (odds ratio $=3.2 ; P=0.089$ ). The following demographic and clinical variables were not statistically significant in our model: sex, age, history of glaucoma, diagnosis requiring intravitreal bevacizumab injection, previous injections, and eye (OS [left eye] or OD [right eye]).

\section{Discussion}

Intravitreal injection has become an increasingly common intervention for the treatment of retinal disease. Intravitreal bevacizumab is being positioned as a major treatment 


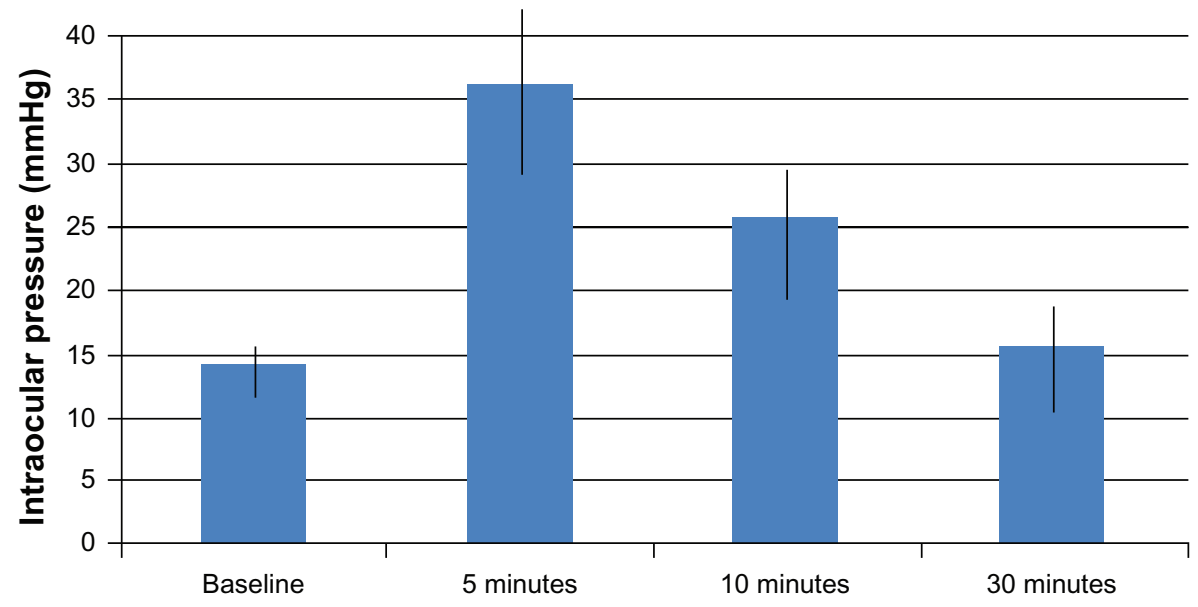

Figure I Relationship between intraocular pressure and various time intervals after intravitreal injection.

modality for exudative AMD, which is the leading cause of new blindness in North America. ${ }^{1}$

Our study showed that a $0.05 \mathrm{~mL}$ intravitreal bevacizumab injection has an excellent safety profile with respect to sustained short-term IOP changes. Although there was a statistically significant higher IOP at 30 minutes after injection when compared with baseline, this difference $(1.4 \mathrm{mmHg})$ was not clinically significant. The vast majority $(96.1 \%)$ of patients had an IOP of less than $25 \mathrm{mmHg}$ after 30 minutes. However, our study showed that IOP rises substantially in some patients immediately after injection, but it rapidly normalizes. Transient increases in IOP are not uncommon with the addition of fluid into the vitreous cavity. There have been several published reports demonstrating short-term, transient increases in IOP after injection of intravitreal anti-VEGF agents, which were shown to return to $<25 \mathrm{mmHg}$ within 30 to 60 minutes without IOP-lowering therapy. ${ }^{11-14}$ These studies suggested increases in IOP tend to be higher in phakic patients. ${ }^{11}$ Frenkel et al ${ }^{15}$ concluded that intraocular pressure spikes after intravitreal injection of anti-VEGF agents are common and in most cases transient, so routine prophylactic use of IOP lowering medications is not necessary. Therefore, frequent IOP monitoring for normalization after intravitreal injections may not be necessary on the day of injection, as only 7 patients (13.45\%) experienced an IOP spike above $50 \mathrm{mmHg}$. This likely induces ocular perfusion pressures below the auto-regulatory range of optic nerve head blood flow. ${ }^{16}$ Moreover, acute deformations in the contour of the lamina cribrosa also occur at these IOPs. ${ }^{17,18}$ The long-term consequences of these transient events are unknown. However, the potential for negative sequelae should be considered, especially in patients with advanced glaucomatous optic neuropathy. A pre-injection anterior chamber paracenthesis as prophylaxis may be considered for these patients.
Two patients developed high IOP after intravitreal injection: the IOP normalized over 1.5 hours for one patient, while the other one required a short course of IOP-lowering medications. The latter patient was male, relatively young ( $<50$ years), had a 30 -minute IOP of $45 \mathrm{mmHg}$, and was being treated for diabetic macular edema. He did not have previous glaucoma but had received an intravitreal injection of a corticosteroid within the previous year; therefore, it is possible that this patient sustained some damage to the trabecular meshwork as a result of the previous steroid injection and was consequently unable to adequately clear the additional volume of fluid from the injection. Our sample was too small to study this question adequately, but future research into IOP change after intravitreal bevacizumab injection in patients with previous corticosteroid injection may be helpful.

Benz et $\mathrm{al}^{6}$ studied short-term IOP changes after injection of $0.1 \mathrm{~mL}$ intravitreal TA. They found that $7.1 \%$ of patients had an IOP greater than $25 \mathrm{mmHg}$ at 30 minutes after injection and postulated that the IOP rise after injection may be mechanical, as a result of the $2.5 \%$ increase in vitreous volume. In our study, two patients (3.84\%) had IOP values over $25 \mathrm{mmHg}$ after 30 minutes. The most obvious reason for this difference compared to the previous study is that we injected less medication $(0.05 \mathrm{~mL}$ versus $0.1 \mathrm{~mL})$ into the vitreous cavity. In addition, bevacizumab is not known to cause IOP increases in the long-term, whereas corticosteroids have a known long-term risk of ocular hypertension linked to corticosteroid-dependent mechanical and biochemical changes to the trabecular meshwork ${ }^{19,20}$ resulting in increased aqueous outflow resistance, owing to an accumulation of extracellular matrix material in the trabecular meshwork. ${ }^{20}$ 
Many studies have investigated short-term IOP changes after intravitreal administration of TA. ${ }^{6-8}$ Our study is prospective and has a relatively larger sample size compared to other similar safety studies. ${ }^{6-8}$ We deliberately used minimal exclusion criteria in order to simulate the safety of this treatment modality in the real world; consequently, this can be considered a strength of the study.

In addition, we demonstrated excellent inter-rater reliability with respect to IOP measurement. One weakness of our study was not quantifying medication reflux at the time of injection. This has been done in the past when short-term IOP changes after intravitreal injection of corticosteroids have been studied ${ }^{6}$ and might have enabled better prediction for patients with immediate IOP pressure spikes. However, vitreous reflux is a subjective measure and is especially difficult to quantify with intravitreal bevacizumab injections since the medication is clear. This is different from the reflux of intravitreal TA, which has a milky-white appearance and would be easier to quantify. Therefore, it is uncertain whether attempting to quantify vitreous reflux of the bevacizumab would have added reliable data to our study.

\section{Conclusion}

Intravitreal bevacizumab injections have an excellent safety profile with respect to short-term IOP changes. Extreme transient IOP elevations may occur in some patients. Clinicians should consider checking IOP after intravitreal bevacizumab injection as a precaution especially in patients with glaucoma.

Intraocular pressure spikes after intravitreal injections of bevacizumab are common and in the majority of cases are transient so routine prophylactic use of anti-glaucoma medications before or after injection is ineffective in preventing IOP elevations. Anti-glaucoma medications should be prescribed when IOP values exceed $25 \mathrm{mmHg} 2$ hours after injection.

\section{Acknowledgments}

We thank Biometricians for statistical analysis support.

\section{Disclosure}

The authors report no conflicts of interest in this work.

\section{References}

1. Fung AE, Rosenfeld PJ, Reichel E. The International Intravitreal Bevacizumab Safety Survey: using the internet to assess drug safety worldwide. Br J Ophthalmol. 2006;90(11):1344-1349.
2. Jorge R, Costa RA, Calucci D, Cintra LP, Scott IU. Intravitreal bevacizumab (Avastin) for persistent new vessels in diabetic retinopathy (IBEPE study). Retina. 2006;26(9):1006-1013.

3. Higashide T, Murotani E, Saito Y, Ohkubo S, Sugiyama K. Adverse events associated with intraocular injections of bevacizumab in eyes with neovascular glaucoma. Graefes Arch Clin Exp Ophthalmol. 2012;250(4):603-610.

4. Mansour AM, Shahin M, Kofoed PK, Parodi MB, Shami M, Schwartz SG; Collaborative Anti-VEGF Ocular Vascular Complications Group. Insight into 144 patients with ocular vascular events during VEGF antagonist injections. Clin Ophthalmol. 2012;6:343-363.

5. Manousaridis K, Talks J. Macular ischaemia: a contraindication for anti-VEGF treatment in retinal vascular disease? Br J Ophthalmol. 2012;96(2):179-184.

6. Benz MS, Albini TA, Holz ER, et al. Short-term course of intraocular pressure after intravitreal injection of triamcinolone acetonide. Ophthalmology. 2006;113(7):1174-1178.

7. Dwinger MC, Pieper-Bodeewes I, Eter N, Holz FG. [Variations in intraocular pressure (IOP) and necessity for paracentesis following intravitreal triamcinolone injection]. Klin Monbl Augenheilkd. 2005;222(8):638-642. German.

8. Singh IP, Ahmad SI, Yeh D, et al. Early rapid rise in intraocular pressure after intravitreal triamcinolone acetonide injection. Am J Ophthalmol. 2004;138(2):286-287.

9. Quigley HA, Anderson DR. Distribution of axonal transport blockade by acute intraocular pressure elevation in the primate optic nerve head. Invest Ophthalmol Vis Sci. 1977;16(7):640-644.

10. Quigley H, Anderson DR. The dynamics and location of axonal transport blockade by acute intraocular pressure elevation in primate optic nerve. Invest Ophthalmol. 1976;15(8):606-616.

11. Hollands H, Wong J, Bruen R, Campbell RJ, Sharma S, Gale J. Short-term intraocular pressure changes after intravitreal injection of bevacizumab. Can J Ophthalmol. 2007;42(6):807-811.

12. Kim JE, Mantravadi AV, Hur EY, Covert DJ. Short-term intraocular pressure changes immediately after intravitreal injections of anti-vascular endothelial growth factor agents. Am J Ophthalmol. 2008;146(6):930-934. e1.

13. Mojica G, Hariprasad SM, Jager RD, Mieler WF. Short-term intraocular pressure trends following intravitreal injections of ranibizumab (Lucentis) for the treatment of wet age-related macular degeneration. Br J Ophthalmol. 2008;92(4):584.

14. Bakri SJ, Pulido JS, McCannel CA, Hodge DO, Diehl N, Hillemeier J. Immediate intraocular pressure changes following intravitreal injections of triamcinolone, pegaptanib, and bevacizumab. Eye (Lond). 2009;23(1):181-185.

15. Frenkel MP, Haji SA, Frenkel RE. Effect of prophylactic intraocular pressure-lowering medication on intraocular pressure spikes after intravitreal injections. Arch Ophthalmol. 2010;128(12):1523-1527.

16. Michelson G, Groh MJ, Langhans M. Perfusion of the juxtapapillary retina and optic nerve head in acute ocular hypertension. Ger J Ophthalmol. 1996;5(6):315-321.

17. Riva CE, Hero M, Titze P, Petrig B. Autoregulation of human optic nerve head blood flow in response to acute changes in ocular perfusion pressure. Graefes Arch Clin Exp Ophthalmol. 1997;235(10): 618-626.

18. Yan DB, Coloma FM, Metheetrairut A, Trope GE, Heathcote JG, Ethier CR. Deformation of the lamina cribrosa by elevated intraocular pressure. Br J Ophthalmol. 1994;78(8):643-648.

19. Jonas JB, Degenring RF, Kreissig I, Akkoyun I, Kamppeter BA. Intraocular pressure elevation after intravitreal triamcinolone acetonide injection. Ophthalmology. 2005;112(4):593-598.

20. Jones R, Rhee DJ. Corticosteroid-induced ocular hypertension and glaucoma: a brief review and update of the literature. Curr Opin Ophthalmol. 2006;17(2):163-167. 


\section{Publish your work in this journal}

Clinical Ophthalmology is an international, peer-reviewed journal covering all subspecialties within ophthalmology. Key topics include: Optometry; Visual science; Pharmacology and drug therapy in eye diseases; Basic Sciences; Primary and Secondary eye care; Patient Safety and Quality of Care Improvements. This journal is indexed on

Submit your manuscript here: http://www.dovepress.com/clinical-ophthalmology-journal
PubMed Central and CAS, and is the official journal of The Society of Clinical Ophthalmology (SCO). The manuscript management system is completely online and includes a very quick and fair peer-review system, which is all easy to use. Visit http://www.dovepress.com/ testimonials.php to read real quotes from published authors. 